\title{
PENINGKATAN KETERAMPILAN SOSIAL DAN MOTORIK HALUS ANAK MELALUI PEMBELAJARAN BERBASIS PROYEK
}

\author{
Increasing Children's Social and Fine Motor Skills Through \\ Project-Based Learning
}

\author{
Wuni Arum Sekar Sari \\ Institut Agama Islam Tribakti Kediri \\ E-mail:swuniarum@gmail.com
}

\begin{tabular}{l|l|l}
\hline DOI: $10.53754 /$ edusia.v1i1.34 & \\
\hline Received: 2021-07-17 & Revised: 2021-07-24 & Approved: 2021-07-27 \\
\hline
\end{tabular}

\begin{abstract}
This study examines the effect of project-based learning on children's socialemotional development and children's fine motoric development. This study uses a QuasiExperimental Design. Control-Group Design (Pre-test and Post Test) or Nonequivalent [Pretest and Post Test] Control-Group Design, the experimental group (A) and the control group (B), were selected without a random assignment procedure. In these two groups, both pretest and posttest were carried out. Only the experimental group (A) was treated. This research was conducted at RA Uniform Debit and RA Kusuma Mulia, Ngino, Plemahan, Kediri. Data were collected using observation sheets, descriptive statistical data analysis, and paired $\mathrm{t}$-test with alpha $<0.05$. Based on the results of different tests with the Paired $t$-test, the Sig. As much as 0.000 , where this value is less than 0.05 , reject $\mathrm{H} 1$ and accept H0, there are differences in social-emotional development and fine motor skills between before (pretest) and after (posttest) getting project-based learning the experimental group and the control group. The average value shows that the social-emotional development after being given the Project-Based learning was more significant than the social-emotional development, namely 26.03> 20.44 in the experimental group and 22.10> 20.23 in the control group. Likewise, fine motor development before being given the Project-Based learning, namely 14.97> 11.84 in the experimental group and 13.03> 11.97 in the control group. This means that the project-based learning given to RA students in Plemahan, Kediri is more effective than learning in the control group.
\end{abstract}

Keywords: Project-based learning; social-emotional; fine motoric

Abstrak: Penelitian ini mengaji pengaruh pembelajaran berbasis proyek terhadap perkembangan sosial-emosional anak dan perkembangan motorik halus anak. Penelitian ini menggunakan Desain Quasi Eksperimental. Desain Kelompok Kontrol (Pre-test dan Post Test) atau Tidak Ada [Pretest and Post Test] Desain Kelompok Kontrol, kelompok eksperimen (A) dan kelompok kontrol (B), dipilih tanpa prosedur penugasan acak. Pada kedua kelompok ini dilakukan pretest dan posttest. Hanya kelompok eksperimen (A) diperlakukan. Penelitian ini dilakukan di RA Uniform Debit dan RA Kusuma Mulia Kecamatan, Ngino, Plemahan, Kabupaten Kediri. Pengumpulan data menggunakan lembar observasi, analisis data statistik deskriptif, dan uji-t berpasangan dengan alpha $<0,05$. Berdasarkan hasil uji beda dengan Paired t-test diperoleh nilai Sig. Sebanyak 0,000 dimana nilai ini kurang dari 0,05, menolak $\mathrm{H} 1$ dan menerima $\mathrm{H} 0$, terdapat perbedaan perkembangan sosial emosional dan motorik halus antara sebelum (pretest) dan setelah (posttest) mendapatkan pembelajaran berbasis proyek kelompok eksperimen dan kelompok eksperimen. kelompok kontrol. Nilai rata-rata tersebut menunjukkan bahwa perkembangan sosial-emosional setelah diberikan pembelajaran 
berbasis Proyek lebih signifikan dibandingkan dengan perkembangan sosial-emosional, yaitu 26,03>20,44 pada kelompok eksperimen dan 22,10>20,23 pada kelompok kontrol. Begitu juga perkembangan motorik halus sebelum diberikan pembelajaran Project Based yaitu 14,97>11,84 pada kelompok eksperimen dan 13,03>11,97 pada kelompok kontrol. Artinya pembelajaran berbasis proyek yang diberikan kepada siswa RA di Kecamatan, Plemahan, Kabupaten Kediri lebih efektif dibandingkan pembelajaran pada kelompok kontrol.

Kata Kunci: Pembelajaran berbasis proyek; sosial-emosional; motorik halus

\section{PENDAHULUAN}

Periode emas dalam masa perkembangan (the golden age) terjadi pada anak usia dini yang artinya berada pada masa sensitive atau peka dalam menerima berbagai rangsangan. Ini berarti sama dengan pernyataan bahwa ajaran dasar yang melekat pada masa kanak-kanak di awal usianya akan mampu menentukan pribadi anak pada saat menyesuaikan diri dengan orang lain. Maka di sinilah pentingnya mengembangkan segala aspek yang meliputi perkembangan anak dengan menanamkan perilaku sejak dini untuk mempertahankan pembiasaan yang baik di sepanjang hidupnya.

Adapun aspek perkembangan yang dapat di analisis pada anak usia dini antara lain: fisik motorik, seni dan kreativitas, kognitif, bahasa, moral dan nilai-nilai agama, dan dari segi sosial emosional ${ }^{1}$. Pada hakikatnya, setiap anak lahir dengan memiliki berbagai potensi yang melekat pada dirinya untuk menemani tumbuh kembang yang mengikuti kondisi dan situasi yang mampu merangsang potensi anak tersebut. Inilah menjadi aspek penting yang perlu dikembangkan sesuai dengan yang menjadi tujuan pada pendidikan anak usia dini, yaitu menyiapkan setiap anak untuk tumbuh kembangnya secara komprehensif. Salah satu aspek yang perlu dikembangkan dalam tumbuh kembang anak usia dini yaitu perkembangan emosional yang memiliki tingkat berbeda-beda.

Dalam lingkungan masyarakat, setiap orang akan tidak bisa hidup tanpa pertolongan orang lain, sehingga perkembangan sosial emosional sangat akan dibutuhkan bagi anak usia ${ }^{2}$. Bahkan saat ini kemampuan sosial emosional telah dikenal sebagai aspek yang memiliki pengaruh paling besar terhadap tingkat keberhasilan seseorang. Semakin tinggi kemampuan sosial emosional seseorang maka akan semakin besar kemungkinan keberhasilannya ${ }^{3}$. Pernyataan ini didukung oleh penelitian Winarno bahwa orang yang memiliki akademis rata-rata tetapi mempunyai kemampuan sosial emosional yang lebih besar dalam kehidupannya

${ }^{1}$ Ahmad Mansur, Metode Penelitian Dan Teknik Penulisan Laporan Karya Ilmiah (Bandung: PAAP FEBUNPAD, 2011), 22.

2 Fadillah, Implementasi Kurikulum 2013 Dalam Pembelajaran SD/MI, SMP/MTs, Dan SMA/MAN (Yogyakarta: Ar-Ruzz Media, 2014), 51, https:/ / onesearch.id/Record/IOS3605.INLIS000000000012011.

${ }^{3}$ Robert A Baron and Gideon D Markman, “Beyond Social Capital: The Role of Entrepreneurs' Social Competence in Their Financial Success," Journal of Business Venturing 18, no. 1 (January 2003): 41-60, https://doi.org/10.1016/S0883-9026(00)00069-0. 
akan lebih berhasil jika dibandingkan dengan orang yang mempunyai kemampuan sosial emosional rata-rata tetapi mempunyai kemampuan akademis yang lebih tinggi. 4

Ada beberapa hal yang mendasar sehingga dapat mendorong pentingnya pengembangan social emosional. Pertama, permasalahan yang terjadi di sekitar lingkungan anak semakin kompleks, yang banyak memberikan pengaruh berupa tekanan dan perkembangan emosi social anak yaitu perkembangan pada ilmu pengetahuan dan perkembangan dari sisi teknologi (IPTEK). Kedua, adalah kegiatan menanamkan kesadaran kepada anak bahwa seorang anak adalah seorang praktisi dan merupakan investasi di masa depan yang butuh dipersiapkan secara maksimal, baik dari segi perkembangan keterampilan sosialnya maupun emosinya. Ketiga, harus diberikan fasilitas secara optimal agar tidak melewatkan fase pada tiap perkembangannya, karena rentang usia sangat penting pada anak yang memiliki kemampuan terbatas. Keempat, sebagai bekal kehidupan yang nyata, anak lebih membutuhkan Emotional Quotient (EQ) dari pada berkembangan dengan Intelligence Quotient (IQ) semata. Kelima, tumbuhnya sikap yang sadar pada setiap anak tentang adanya tuntutan untuk diberikan bekal dalam hidupnya serta mempunyai kecerdasan sosial emosional sejak dini ${ }^{5}$.

Perkembangan sosial emosional yaitu sebuah capaian perkembangan atas kematangan emosi dalam sebuah hubungan sosial yang terjadi di masyarakat. Dengan kata lain perkembangan sosial emosional dapat dimaknai sebagai proses belajar agar dapat beradaptasi terhadap aturan yang ada dalam kelompok, tradisi dan moral; menyatukan diri menjadi suatu satu kesatuan, saling menjalin komunikasi dan melakukan kerja sama6 ${ }^{6}$ Disebutkan pada standar kurikulum PAUD (2013) bahwa anak pada usia 4-5 tahun telah mampu berinteraksi dengan teman sejawatnya, menjaga keamanan diri sendiri, menunjukkan sikap yang mandiri, mampu menunjukkan sikap emosi yang wajar, menunjukkan sikap disiplin dan mulai menunjukkan sikap bertanggung jawab.

Perkembangan sosial emosional berhubungan positif dengan perkembangan motorik ${ }^{7}$. Pada hakikatnya, setiap perkembangan pada anak tidak mampu diputuskan antara satu dengan yang lainnya, ini berarti hal tersebut sejalan dengan adanya fungsi pengembangan pada motorik halus yaitu mendukung adanya aspek

\footnotetext{
4 Jacinta Winarno, “Emotional Intelegence Sebagai Salah Satu Faktor Penunjang Prestasi Kerja," Jurnal Manajemen Maranatha 8, no. 1 (2008).

${ }_{5}^{5}$ Ali Nugraha, Pengembangan Pembelajaran Sains Pada Anak Usia Dini (Jakarta: Depdiknas (Dit.PPTK \& KPT), 2005), 15.

6 Syamsu Yusuf, Psikologi Perkembangan Anak Dan Remaja (Bandung: PT Remaja Rosdakarya, 2007).

7 Jan P. Piek, Grant B. Baynam, and Nicholas C. Barrett, "The Relationship between Fine and Gross Motor Ability, Self-Perceptions and Self-Worth in Children and Adolescents," Human Movement Science 25, no. 1 (February 2006): 65-75, https:// doi.org/10.1016/j.humov.2005.10.011.
} 
lain seperti sosial emosional ${ }^{8}$. Adapun karakteristik umum fisik motorik yang ada pada anak usia 4-5 tahun yaitu koordinasi tangan dan mata semakin baik.

Kurikulum PAUD (2013) menyebutkan otot-otot kecil diantaranya membuat berbagai macam model atau bentuk dengan menggunakan media plasticine, meremas kertas, menjiplak dan meniru membuat garis, meniru melipat kertas sederhana, merekat atau menempel, menyusun berbagai bentuk dengan menggunakan balok, meronce dan memegang alat tulis. Sedangkan koordinasi mata dan tangan yang disebutkan dalam kurikulum PAUD (2013) adalah mampu mengurus diri pribadi dengan sedikit memerlukan bantuan, menjahit jelujur 10 lubang dengan tali sepatu, menggunting dengan menyesuaikan bentuk melingkar, zigzag, dan lain-lain, mampu memantulkan objek (bola besar) sambil berjalan atau bergerak, memantulkan bola besar yang berada pada posisi diam di tempat, melambungkan dan menangkap objek (bola besar).

Meningkatkan perkembangan sosial emosional dan motorik halus anak di lingkungan sekolah sangat ditentukan oleh permainan yang tepat. Pendidik harus mampu menerapkan berbagai permainan yang berbeda sehingga anak merasa tidak mudah bosan dalam mengikuti setiap kegiatan pembelajaran karena pendidikan pada anak usia dini tidak hanya memiliki tujuan untuk memenuhi target kurikulum, keinginan pemerintah, keinginan masyarakat maupun orang tua seperti membaca, menulis dan berhitung akan tetapi pendidikan bertujuan untuk menstimulasi anak agar sesuai dengan tahap perkembangannya, sehingga pendidik PAUD juga harus menguasai metode pembelajaran yang tepat, menyenangkan, kreatif dan inovatif.

Di antara metode yang menarik dan menyenangkan adalah Pembelajaran berbasis proyek. Seperti yang dikatakan Gaer yang menyatakan bahwa "pembelajaran berbasis proyek memiliki potensi yang besar untuk memberi pengalaman belajar yang lebih menarik dan bermakna bagi siswa" 9 . Pembelajaran berbasis proyek adalah sebagian cara yang digunakan untuk memberikan pengalaman pada bidang belajar anak dengan menghadapkan anak secara langsung pada permasalahan sehari-hari dengan pemecahan masalah yang dilakukan secara berkelompok. Pembelajaran berbasis proyek mampu mengembangkan aspek sosial khususnya kemampuan kerjasama anak, sebab anak melakukan interaksi dengan teman lainnya dan dengan berinteraksi akan memberikan pengajaran kepada anak untuk dapat memberikan respon, menanggapi dalam hal memberi, menerima atau menolak dengan menggunakan ide dan perilaku lainnya ${ }^{10}$.

\footnotetext{
8 M.S. Sumantri, Model Pengembangan Keterampilan Motorik Anak Usia Din (Jakarta: Dinas Pendidikan, 2005), 146.

${ }_{9}$ Wena Made, Strategi Pembelajaran Inovatif Kontemporer: Suatu Tinjauan, Konseptual Operasional (Jakarta: PT Bumi Aksara, 2011), 144.

10 Endah Prayuanti, "Peningkatan Kemampuan Bekerjasama Melalui Metode Bermain Pada Kelompok B Di TK PKK 54 Pucung Pendowoharjo Sewon Bantul” (FIP UNY, 2014).
} 
Selain dapat mengembangkan perkembangan sosial emosional, Pembelajaran berbasis proyek juga dapat mengembangkan perkembangan motorik halus anak. Hal ini sama dengan pendapat yang dinyatakan oleh ${ }^{11}$, yang mengungkapkan hal yang sama, yaitu metode pembelajaran berbasis proyek adalah salah satu wujud bentuk kegiatan dalam memberikan solusi pemecahan masalah secara bersama-sama, di mana dengan bekerja secara berkelompok anak dapat belajar memiliki rasa tanggung jawab, mampu menjalin hubungan dan mampu belajar menghargai orang lain.

Penelitian mengenai pembelajaran berbasis proyek bukan hal baru, temuan Kusadi, et.al menilite tentang signifikasi metode ini terhadap keterampilan sosial dan kemampuan berfikir kreatif. ${ }^{12}$ Selain itu, Bambang Waluyo baru-baru ini melakukan upaya peningkatan siswa dengan menerapkan pembelajaran berbasis proyek. ${ }^{13}$ Demikian halnya dengan Yulianti, mendesain pembelajaran berbasis proyek ini dan mempraktikannya terhadap siswa kelas IX. ${ }^{14}$ Penelitian yang mirip dari segi metode, sebagaimana dilakukan oleh Fadila, yang menerapkan metode quasi eksperimen pada Tunagrahita tingkat SMA. ${ }^{15}$ Selain itu, Anisa Yunita Sari pernah menerapkan metode ini pada anak usia dini, hanya saja ia tidak menggunakan metode quasi eksperimental. ${ }^{16}$ Terlihat bahwa penggunaan metode ini terhadap anak usia 4-5 tahun menggunakan metode quasi-eksperimental belum diterapkan, untuk itu penelitian ini menjadi tambahan terkait penerapan pembelajaran berbasis proyek dalam berbagai tingkatan pendidikan.

Pembelajaran berbasis proyek yang akan dilakukan dalam penelitian ini adalah bermain pasir membuat bentuk-bentuk sesuai tema kebutuhanku. Dengan begitu, anak akan terlatih sosialnya ketika berkomunikasi dengan teman nya menceritakan itu bentuk apa, melatih emosional dan motorik halusnya dengan berlatih sabar dan berjuang menyelesaikan hasil karyanya, sampai pada anak bangga dengan hasil karyanya sendiri serta menghargai hasil karya teman-temannya. Bisa juga anak bekerjasama dalam menyelesaikan karya tersebut.

11 Yus Anita, Penilaian Perkembangan Belajar Taman Kanak-Kanak (Jakarta: Kencana, 2012), 174.

12 Ni Made Risa Kusadi, I Putu Sriartha, and I Wayan Kertih, “Model Pembelajaran Project Based Learning Terhadap Keterampilan Sosial Dan Berpikir Kreatif," Thinking Skills and Creativity Journal 3, no. 1 (2020): 18-27, https://doi.org/http://dx.doi.org/10.23887/tscj.v3i1.24661.

13 Bambang Waluyo, "UPAYA MENINGKATKAN PRESTASI BELAJAR, KEMAMPUAN PRESENTASI DAN DISKUSI MATERI KEUNGGULAN LOKASI INDONESIA PELAJARAN IPS, DAN SIKAP SISWA KELAS VIII.B UPTD SMPN 4 METRO MELALUI PEMBELAJARAN BERBASIS PROYEK DENGAN PENGUATAN DISKUSI TA 2019/2020," Jurnal Guru Indonesia 1, no. 4 (July 12, 2021), https:/ / doi.org/10.24127/jgi.v1i4.1142.

14 Yulianti, Yusuf Hartono, and Budi Santoso, "DESAIN PEMBELAJARAN BERBASIS PROYEK PADA MATERI PENYAJIAN DATA DI KELAS IX ," Numeracy 2, no. 2 SE-Articles (October 31, 2015): 1-12, https:// doi.org/10.46244/numeracy.v2i2.163.

15 Fadila Sefni, "EFEKTIFITAS PEMBELAJARAN BERBASIS PROYEK PADA PEMBELAJARAN KETERAMPILAN BAGI ANAK TUNAGRAHITA SEDANG KELAS X SMALB DI YPAC SUMBAR (Quasi Eskperimen)," Jurnal Penelitian Pendidikan Khusus $3, \quad$ no. 3 (2014), https://doi.org/https://doi.org/10.24036/jupe38440.64.

16 Anisa Yunita Sari, "IMPLEMENTASI PEMBELAJARAN PROJECT BASED LEARNING UNTUK ANAK USIA DINI," MOTORIC 1, no. 1 (April 28, 2018): 10, https:/ /doi.org/10.31090/paudmotoric.v1i1.547. 
Riset ini menggunakan pendekatan penelitian kuantitatif. Adapun jenis penelitian yang peneliti pilih adalah penelitian kuantitatif berbasis eksperimen. Desain penelitian yang digunakan pada penelitian ini adalah Rancangan KelompokKontrol (Pre-test and Post Test) Non-ekuivalen (Non-equivalen [Pre-test and Post Test] Control-Group Design) yaitu kelompok pada eksperimen (A) dan kelompok pada kontrol (B) terlebih dahulu dilakukan seleksi tanpa menggunakan prosedur penempatan secara acak (without random assignment (Creswell, 2014:242). Kemudian, dilakukan pre-test dan post-test pada dua kelompok tersebut. Treatment hanya dilakukan pada kelompok eksperimen (A) saja. Desain penelitian ini menyesuaikan dengan tujuannya yaitu untuk mengetahui adanya pengaruh yang ada pada pembelajaran berbasis proyek terhadap perkembangan sosial emosional dan motorik halus anak.

Sampel pada penelitian ini adalah RA Seragam Sebet sebagai kelas eksperimen dengan total responden sejumlah 32 anak dan kelas kontrol yang ada dalam penelitian ini adalah RA Kusuma Mulia Ngino yang terdiri dari 30 anak dengan pembelajaran menggunakan media gambar dan penjelasan secara verbal. Penelitian dilakukan di lembaga RA Seragam Sebet dan RA Kusuma Mulia Ngino Kecamatan Plemahan Kabupaten Kediri pada bulan Juni semester genap tahun pelajaran 2016-2017.

Dalam penelitian ini, observasi yang dilakukan adalah observasi secara sistematis yaitu instrumen observasi digunakan sebagai pedoman dalam melakukan kegiatan observasi. Pada penelitian ini, observasi memiliki tujuan untuk mendeskripsikan pengaruh kegiatan pembelajaran dengan memakai Pembelajaran berbasis proyek di RA Kecamatan Plemahan Kabupaten Kediri. Pada penelitian ini, pengukuran penilaian merujuk pada pedoman penilaian yang ada pada kurikulum 2013 dengan memakai simbol BB (Belum Berkembang), MB (Mulai Berkembang), BSH (Berkembang Sesuai Harapan) dan BSB (Berkembang Sangat Baik).

Penelitian ini memakai Instrumen berupa lembar observasi kegiatan perkembangan sosial emosional dan motorik halus anak pada kegiatan Pembelajaran berbasis proyek. Pada penelitian ini, statistik deskriptif digunakan agar dapat mendeskripsikan variabel perkembangan sosial emosional dan motorik halus anak usia 4-5 tahun.

Uji analisis berupa uji normalitas dan homogenitas dilakukan terlebih dahulu sebelum diadakan kegiatan analisis data, untuk menguji hipotesis digunakan analisis statistik inferensial. Untuk keperluan tersebut digunakan uji Kolmogorov-Smirnov (KS), dengan menggunakan bantuan komputer program SPSS 23 Windows Evaluation Version.

Analisis statistik uji-t (paired t-test) ini dipakai untuk mengetahui ada perbedaan perkembangan sosial emosional dan motorik halus anak antara sebelum (pretest) dan 
sesudah (posttest) mendapatkan perlakukan (treatment) berupa pembelajaran dengan kegiatan Pembelajaran berbasis proyek.

Untuk dapat mengetahui ada atau tidaknya pengaruh treatment terhadap perubahan yang ada pada sebelum dan sesudah treatment, maka didasarkan pada perbedaan skor hasil pengukuran pre dan posttest.

\section{PEMBAHASAN}

\subsection{Hasil Penelitian}

Dalam hal ini peneliti memaparkan tentang hasil dari uji normalitas, homogenitas dan uji beda dengan paired t test. Objek dalam penelitian ini terbagi menjadi dua kelompok yakni Kelompok A di RA Kecamatan Plemahan Kabupaten Kediri, di mana jumlah sampel 32 anak sebagai kelas eksperimen (diberikan treatment dengan Pembelajaran berbasis proyek) dan 30 anak sebagai kelas kontrol (pembelajaran tradisional). Penelitian ini memiliki tujuan untuk menguji apakah terdapat pengaruh Pembelajaran berbasis proyek terhadap perkembangan sosial emosional dan perkembangan motorik anak usia 4-5 tahun di RA Kecamatan Plemahan. Tes kemampuan untuk mengukur perkembangan sosial emosional dan motorik halus dilakukan 2 kali yaitu pre-test dan post-test.

Penelitian ini diawali dengan memberikan observasi awal (pretest) pada kelompok kontrol dan kelompok eksperimen. Observasi awal (pretest) ini dilaksanakan agar dapat mengetahui perkembangan sosial emosional dan motorik halus awal anak. Pada observasi awal (pretest) ini dilakukan dengan memberikan lembar penilaian observasi dan dokumentasi dari kegiatan pembelajaran kepada anak anak sebelum mereka diberikan perlakuan.

Kemudian, langkah selanjutnya setelah proses observasi awal (pretest) selesai yaitu, memberikan treatment atau perlakuan. Pada tahap ini, kelompok eksperimen diberikan perlakuan yaitu berupa kegiatan Pembelajaran berbasis proyek. Kegiatan treatment yang diberikan yaitu pada langkah pertama guru menyiapkan materi pembelajaran yang diperlukan dalam kegiatan Pembelajaran berbasis proyek, yaitu kelengkapan bahan yang akan digunakan dalam penyampaian materi. Selanjutnya, guru menjelaskan Pembelajaran berbasis proyek yang dilakukan secara nyata dan langsung, bahan yang digunakan harus benar-benar nyata dan asli. kegiatan Pembelajaran berbasis proyek yang diambil adalah tema kebutuhanku dengan sub tema makanan 4 sehat. 
Peningkatan Keterampilan Sosial dan Motorik Halus Anak Melalui Pembelajaran Berbasis Proyek

Tabel 1. Motorik Halus untuk kelompok A kontrol dan eksperimen antara pre-test dan pos-test

\begin{tabular}{llcccc}
\hline & N & Min & Max & Mean & $\begin{array}{c}\text { Std. } \\
\text { Deviation }\end{array}$ \\
\hline Pretest Kelompok Eksperimen & 32 & 12 & 23 & 20.44 & 2.047 \\
\hline Posttest Kelompok Eksperimen & 32 & 24 & 28 & 26.03 & 1.231 \\
\hline Pretest Kelompok Kontrol & 30 & 12 & 23 & 20.23 & 2.388 \\
\hline Posttest Kelompok Kontrol & 30 & 18 & 24 & 22.10 & 1.296 \\
\hline Valid N (listwise) & 30 & & & & \\
\hline
\end{tabular}

Tabel 2. Statistik Deskriptif Motorik Halus Untuk Kelompok B Kontrol dan Eksperimen Antara Pre-Test dan Pos-Test

\begin{tabular}{llllll}
\hline \multicolumn{7}{c}{ Descriptive Statistics } \\
\hline & $\mathrm{N}$ & Minimum & Maximum & Mean & Std. Deviation \\
\hline Pretest Kelompok Eksperimen & 32 & 11 & 13 & 11.84 & .723 \\
\hline Posttest Kelompok Eksperimen & 32 & 14 & 16 & 14.97 & .822 \\
\hline Pretest Kelompok Kontrol & 32 & 11 & 13 & 12.00 & .803 \\
\hline Posttest Kelompok Kontrol & 30 & 11 & 14 & 13.03 & .809 \\
\hline Valid N (listwise) & 30 & & & & \\
\hline
\end{tabular}

\subsubsection{Uji Normalitas}

One-Sample Kolmogorov-Smirnov Test digunakan untuk uji normalitas data. Dalam hal ini digunakan uji statistik dengan kriteria menggunakan pengujian normalitas data dengan membandingkan probabilitas Asymp. Sig (2-tailed) dengan nilai alpha (a), Kriteria pengujian tersebut adalah dikatakan berdistribusi normal apabila probabilitas Asymp. Sig (sig 2-tailed) > alpha (a). Berikut adalah hipotesis pengujian uji normalitas dengan menggunakan One-Sample Kolmogorov-Smirnov Test:

a. Ho: angka signifikan (Sig) $<0,05$ maka data tersebut tidak berdistribusi normal

b. $\mathrm{H}_{\mathrm{a}}$ : angka signifikan $(\mathrm{Sig})>0,05$ maka data tersebut dikatakan berdistribusi normal.

Tabel 3. Uji Normalitas Variabel Perkembangan Sosial Emosional Untuk Kelompok Kontrol Dan Eksperimen Antara Pre-Test Dan Post-Test

\begin{tabular}{cllll}
\hline \multicolumn{7}{c}{ One-Sample Kolmogorov-Smirnov Test } & & \\
\hline & Pretest & Posttest & Pretest & Posttest \\
& Kelompok & Kelompok & Kelompok & Kelompok \\
& Eksperimen & Eksperimen & Kontrol & Kontrol \\
\hline
\end{tabular}




\begin{tabular}{llllll}
\hline $\mathrm{N}$ & & 32 & 32 & 30 & 30 \\
\hline $\begin{array}{l}\text { Normal } \\
\text { Parameters }\end{array}$ & Mean & 20.44 & 26.03 & 20.23 & 22.10 \\
\cline { 2 - 6 } & Std. Deviation & 2.047 & 1.231 & 2.388 & 1.296 \\
\hline $\begin{array}{l}\text { Most Extreme } \\
\text { Differences }\end{array}$ & Absolute & .202 & .209 & .226 & .203 \\
\cline { 2 - 6 } & Positive & .129 & .166 & .130 & .164 \\
\cline { 2 - 6 } & Negative & -.202 & -.209 & -.226 & -.203 \\
\hline Kolmogorov-Smirnov Z & 1.143 & 1.180 & 1.237 & 1.110 \\
\hline Asymp. Sig. (2-tailed) & .147 & .123 & .094 & .170 \\
\hline Test distribution is Normal. & & & & \\
\hline
\end{tabular}

Tabel 4. Uji Normalitas Variabel Perkembangan Motorik Halus Untuk Kelompok Kontrol dan Eksperimen Antara Pre-Test dan Post-Test

\begin{tabular}{|c|c|c|c|c|c|}
\hline \multicolumn{6}{|c|}{ One-Sample Kolmogorov-Smirnov Test } \\
\hline & & $\begin{array}{l}\text { Pretest } \\
\text { Kelompok } \\
\text { Eksperimen }\end{array}$ & $\begin{array}{l}\text { Posttest } \\
\text { Kelompok } \\
\text { Eksperimen }\end{array}$ & $\begin{array}{l}\text { Pretest } \\
\text { Kelompok } \\
\text { Kontrol }\end{array}$ & $\begin{array}{l}\text { Posttest } \\
\text { Kelompok } \\
\text { Kontrol }\end{array}$ \\
\hline $\mathrm{N}$ & & 32 & 32 & 32 & 30 \\
\hline \multirow{2}{*}{$\begin{array}{l}\text { Normal } \\
\text { Parameters }\end{array}$} & Mean & 11.84 & 14.97 & 12.00 & 13.03 \\
\hline & Std. Deviation & .723 & .822 & .803 & .809 \\
\hline \multirow{3}{*}{$\begin{array}{l}\text { Most } \\
\text { Extreme } \\
\text { Differnces }\end{array}$} & Absolute & .242 & .224 & .206 & .250 \\
\hline & Positive & .227 & .224 & .206 & .216 \\
\hline & Negative & -.242 & -.208 & -.206 & -.250 \\
\hline \multicolumn{2}{|c|}{ Kolmogorov-Smirnov Z } & 1.368 & 1.269 & 1.165 & 1.371 \\
\hline \multicolumn{2}{|c|}{ Asymp. Sig. (2-tailed) } & .057 & .080 & .132 & .057 \\
\hline
\end{tabular}

Perhitungan uji normalitas secara lengkap dapat dilihat dalam tabel 3 dan tabel 4 sedangkan Hasil uji normalitas dengan One-Sample Kolmogorov-Smirnov Test menggunakan software program SPSS, ditunjukkan pada Tabel 5 sebagai berikut: 
Tabel 5. Hasil Uji Normalitas Variabel Perkembangan Sosial Emosional dan Motorik Halus untuk Kelompok Kontrol dan Eksperimen antara Pretest dan Posttest

\begin{tabular}{|c|c|c|c|c|c|c|}
\hline No. & Perkembangan & Kelompok & Data & Asymp. Sig & A & Keterangan \\
\hline 1 & \multirow{4}{*}{ Sosial Emosional } & \multirow{2}{*}{ Eksperimen } & Pre-test & .147 & 0.05 & Normal \\
\hline 2 & & & Post-test & .123 & 0.05 & Normal \\
\hline 3 & & \multirow{2}{*}{ Kontrol } & Pre-test & .094 & 0.05 & Normal \\
\hline 4 & & & Post-test & .170 & 0.05 & Normal \\
\hline 5 & \multirow{4}{*}{ Motorik Halus } & \multirow{2}{*}{ Eksperimen } & Pre-test & .057 & 0.05 & Normal \\
\hline 6 & & & Post-test & .080 & 0.05 & Normal \\
\hline 7 & & \multirow{2}{*}{ Kontrol } & Pre-test & .132 & 0.05 & Normal \\
\hline 8 & & & Post-test & .057 & 0.05 & Normal \\
\hline
\end{tabular}

Berdasarkan Tabel 4.5 di atas, didapatkan hasil bahwa nilai signifikansi untuk uji One-Sample Kolmogorov-Smirnov Test kelompok kontrol dan eksperimen pada perkembangan sosial emosional dan motorik halus pre-test maupun Post-test adalah lebih besar dari 0,05, maka data tersebut berdistribusi normal. Maka alat uji yang digunakan adalah uji beda $t$ paired test untuk mengetahui adanya perbedaan perkembangan sosial emosional dan motorik halus antara sebelum (pretest) dan sesudah (posttest) mendapatkan pembelajaran dengan Pembelajaran berbasis proyek.

\subsubsection{Uji Homogenitas}

Setelah diketahui bahwa nilai pretest dan posttest variabel perkembangan sosial emosional dan motorik halus pada kelompok eksperimen dan kelompok kontrol didapatkan hasil berdistribusi normal, maka langkah berikutnya adalah melakukan uji homogenitas varians data dengan membandingkan angka signifikan Asymp. Sig dengan nilai alpha (a), dengan catatan ketentuan, apabila angka signifikan (Sig) lebih kecil dari a $(0,05)$ maka $\mathrm{H}_{0}$ ditolak, dan sebaliknya jika angka signifikan (Sig) lebih besar dari a $(0,05)$ maka $\mathrm{H}_{a}$ diterima. Hipotesis pengujian uji homogenitas adalah sebagai berikut:

a. $\mathrm{H}_{0}$ : Kedua varian populasi tidak homogen

b. Ha: Kedua varian populasi homogen

Dari data yang didapat pada skor pretest dan posttest kelompok eksperimen dan kelompok kontrol, maka setelah uji homogenitas dilakukan, didapatkan hasil yang dapat ditampilkan pada Tabel 6 yaitu sebagai berikut: 
Tabel 6. Uji Homogenitas Varians Pretest dan Posttest Kelompok Eksperimen dan Kelompok Kontrol Variabel Perkembangan Sosial Emosional

Test of Homogeneity of Variances

\begin{tabular}{lllll} 
& Levene Statistic & df1 & df2 & Sig. \\
\hline Kelompok Eksperimen & 2.918 & 1 & 62 & .093 \\
\hline Kelompok Kontrol & 2.766 & 1 & 60 & .101 \\
\hline
\end{tabular}

Tabel 7. Uji Homogenitas Varians Pretest dan Posttest Kelompok Eksperimen dan Kelompok Kontrol Variabel Perkembangan Motorik Halus

\begin{tabular}{lcccc}
\hline \multicolumn{5}{c}{ Test of Homogeneity of Variances } \\
\hline & Levene Statistic & df1 & df2 & g. \\
\hline $\begin{array}{l}\text { Motorik Halus } \\
\text { (Eksperimen) }\end{array}$ & .325 & 1 & 62 & .571 \\
\hline $\begin{array}{l}\text { Motorik Halus } \\
\text { (Kontrol) }\end{array}$ & .115 & 1 & 60 & .736 \\
\hline
\end{tabular}

Tabel 8. Hasil Uji Homogenitas Varians Pretest dan Posttest Kelompok Eksperimen dan Kelompok Kontrol Variabel Perkembangan Sosial Emosional dan Motorik Halus

\begin{tabular}{|c|c|c|c|c|c|}
\hline No. & Data & & Asymp. Sig & $\mathrm{A}$ & Keterangan \\
\hline 1 & \multirow{2}{*}{$\begin{array}{l}\text { _Perkembangan Sosial } \\
\text { Emosional }\end{array}$} & Eksperimen & .093 & 0.05 & Homogen \\
\hline 2 & & Kontrol & .101 & 0.05 & Homogen \\
\hline 3 & \multirow{2}{*}{$\begin{array}{l}\text { Perkembangan Motorik } \\
\text { Halus }\end{array}$} & Eksperimen & .571 & 0.05 & Homogen \\
\hline 4 & & Kontrol & .736 & 0.05 & Homogen \\
\hline
\end{tabular}

Berdasarkan hasil yang diperoleh dalam tabel 8 di atas, maka diperoleh angka dengan signifikansi pada variabel perkembangan sosial emosional untuk kelompok eksperimen dan kontrol lebih besar dari 0,05 maka $\mathrm{H}_{0}$ ditolak dan $\mathrm{H}_{a}$ diterima, sehingga dapat disimpulkan bahwa data perkembangan sosial emosional pretest dan posttest kelompok eksperimen ataupun kelompok kontrol memiliki varians populasi yang sama atau memiliki sifat homogen Begitu pula pada perkembangan motorik halus untuk kelompok eksperimen dan kontrol lebih besar dari 0,05 maka $\mathrm{H}_{0}$ ditolak dan $\mathrm{H}_{\mathrm{a}}$ diterima, dengan kesimpulan data sosial emosional pretest dan posttest kelompok eksperimen maupun kelompok kontrol bersifat homogen atau memiliki varians populasi yang sama. 


\subsubsection{Interpretasi Data}

Dalam penelitian ini, uji beda dilakukan untuk mengetahui sampai mana perbedaan perkembangan sosial emosional dan motorik halus antara sebelum (pretest) dan sesudah (posttest) mendapatkan pembelajaran berbasis proyek. Berikut langkahlangkah pengujian motorik halus:

$\mathrm{H}_{0}: \mathrm{b}_{1}=\mathrm{b}_{2}=0$, dapat diartikan bahwa tidak ada perbedaan perkembangan sosial emosional antara sebelum (pretest) dan sesudah (posttest) mendapatkan pembelajaran dengan pembelajaran berbasis proyek.

$\mathrm{H}_{\mathrm{a}}: \mathrm{b}_{1} \square \mathrm{b}_{2} \square$ 0, dapat diartikan bahwa ada perbedaan perkembangan sosial emosional antara sebelum (pretest) dan sesudah (posttest) mendapatkan pembelajaran dengan pembelajaran berbasis proyek.

Tingkat signifikan $=0.05$

Daerah kritis: $\mathrm{H}_{\mathrm{a}}$ diterima jika Sig. $>$ (0.05)

Adanya perbedaan pada perkembangan sosial emosional yang terjadi antara sebelum (pretest) dan sesudah (posttest) mendapatkan perkembangan dengan Pembelajaran Berbasis Proyek apakah secara statistik signifikan berbeda atau tidak berbeda secara singkat disajikan pada Tabel 9 sebagai berikut:

Tabel 9. Perbedaan Perkembangan Sosial Emosional Antara Sebelum (pretest) dan Sesudah (posttest) Mendapatkan Pembelajaran dengan Pembelajaran Berbasis Proyek

\begin{tabular}{llllll}
\hline Paired Samples Statistics & Mean & $\mathrm{N}$ & Std. Deviation & Std. Error Mean \\
\hline Pair 1 & $\begin{array}{l}\text { Pretest Sosial Emosional } \\
\text { (Eksperimen) }\end{array}$ & 20.44 & 32 & 2.047 & .362 \\
\hline $\begin{array}{l}\text { Posttest Sosial Emosional } \\
\text { (Eksperimen) }\end{array}$ & 26.03 & 32 & 1.231 & .218 \\
\hline Pair 2 & $\begin{array}{l}\text { Pretest Sosial Emosional } \\
\text { (Kontrol) }\end{array}$ & 20.23 & 30 & 2.388 & .436 \\
\hline $\begin{array}{l}\text { Posttest Sosial Emosional } \\
\text { (Kontrol) }\end{array}$ & 22.10 & 30 & 1.296 & .237 \\
\hline
\end{tabular}




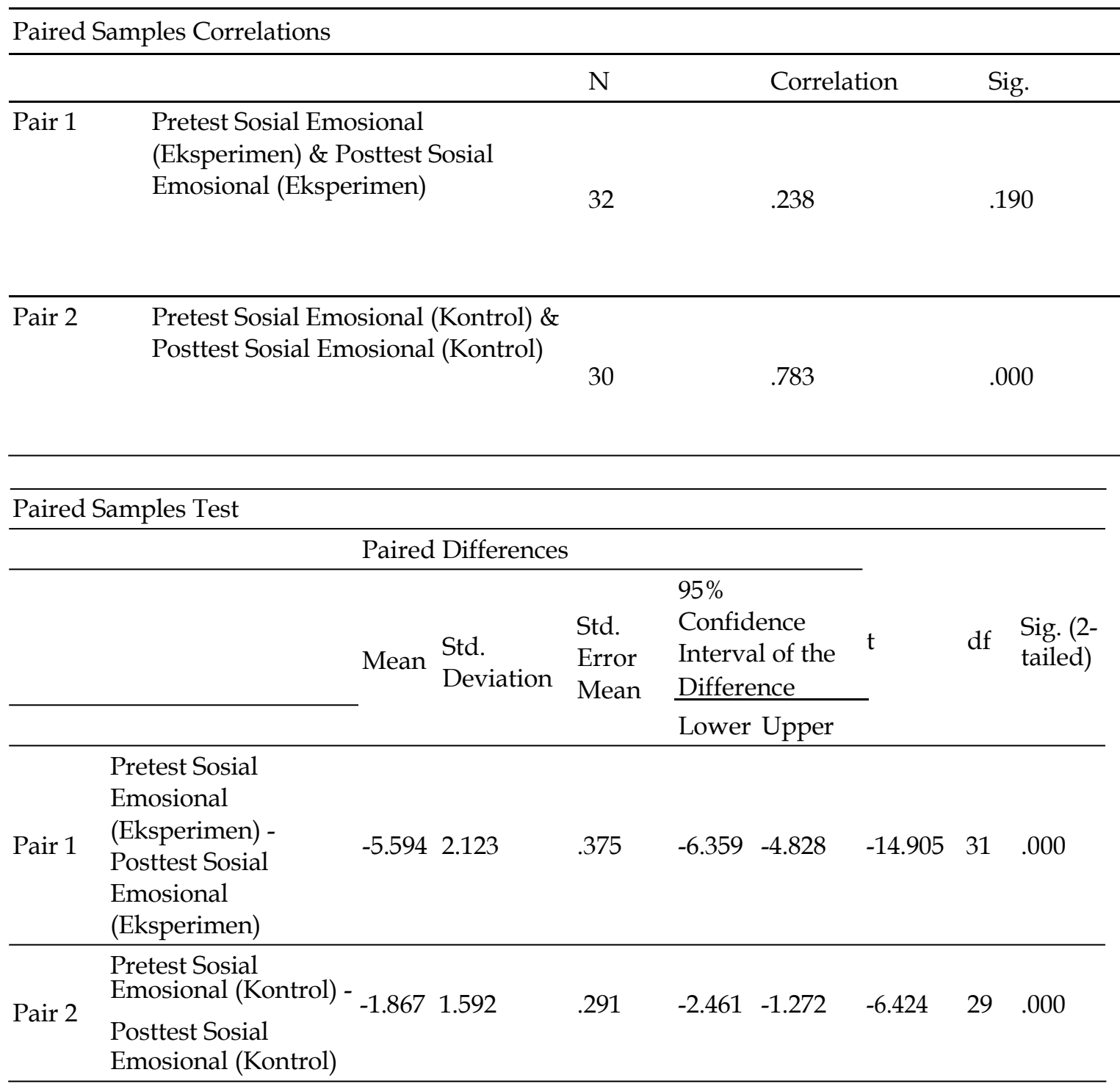

Tabel 10. Uji Beda Perbedaan Perkembangan Sosial Emosional Antara Sebelum (pretest) dan Sesudah (posttest) Mendapatkan Pembelajaran dengan Pembelajaran Berbasis Proyek

\begin{tabular}{|c|c|c|c|c|c|}
\hline Kelompok & Mean & & $\begin{array}{l}\text { Mean } \\
\text { Differences }\end{array}$ & Sig. & Keterangan \\
\hline \multirow{2}{*}{ Eksperimen } & Pretest & 20.44 & \multirow{2}{*}{-5.594} & \multirow{2}{*}{0.000} & \multirow{2}{*}{ Ada perbedaan } \\
\hline & Posttest & 26.03 & & & \\
\hline \multirow{2}{*}{ Kontrol } & Pretest & 20.23 & \multirow{2}{*}{-1.867} & \multirow{2}{*}{0.000} & \multirow{2}{*}{ Ada perbedaan } \\
\hline & Posttest & 22.10 & & & \\
\hline
\end{tabular}

Berdasarkan pada hasil uji beda dengan Paired $t$ test, maka didapatkan nilai Sig. Sebesar 0.000 berarti nilai hitung lebih kecil dari 0.05 , maka $\mathrm{H}_{0}$ di tolak dan $\mathrm{H}_{0}$ diterima yang berarti didapat perbedaan perkembangan sosial emosional antara 
sebelum (pretest) dan sesudah (posttest) mendapatkan pembelajaran dengan Pembelajaran Berbasis Proyek pada kelompok eksperimen dan kelompok kontrol.

Jika dilihat dari nilai rata-rata, perkembangan sosial emosional sesudah diberi pembelajaran dengan Pembelajaran Berbasis Proyek lebih besar daripada perkembangan sosial emosional sebelum diberi Pembelajaran Berbasis Proyek yaitu $26.03>20.44$ pada kelompok eksperimen dan 22.10>20.23 pada kelompok kontrol. Hal ini berarti pembelajaran dengan Pembelajaran Berbasis Proyek yang diberikan pada siswa RA Kecamatan Plemahan Kabupaten Kediri lebih efektif daripada pembelajaran pada kelompok kontrol.

Berikut langkah-langkah pengujian perbedaan perkembangan motorik halus: Hipotesis:

$\mathrm{H}_{0}: \mathrm{b}_{1}=\mathrm{b}_{2}=0$, ini artinya tidak ada perbedaan perkembangan motorik halus antara sebelum (pretest) dan sesudah (posttest) mendapatkan pembelajaran Pembelajaran Berbasis Proyek

$\mathrm{H}_{\mathrm{a}}: \mathrm{b}_{1} \square \mathrm{b}_{2} \square$, ini artinya ada perbedaan perkembangan motorik halus antara sebelum (pretest) dan sesudah (posttest) mendapatkan pembelajaran dengan Pembelajaran Berbasis Proyek.

Tingkat signifikan $=0.05$

Daerah kritis: $\mathrm{H}_{\mathrm{a}}$ diterima jika Sig. $<(0.05)$

Perbedaan perkembangan motorik halus antara sebelum (pretest) dan sesudah (posttest) mendapatkan Pembelajaran Berbasis Proyek apakah secara statistik signifikan berbeda atau tidak berbeda secara singkat disajikan pada Tabel 11 sebagai berikut:

Tabel 11. Perbedaan Perkembangan Motorik Halus Antara Sebelum (pretest) dan Sesudah (posttest) Mendapatkan Pembelajaran Berbasis Proyek

\begin{tabular}{llllll}
\hline Paired Samples Statistics & & & & \\
\hline & & Mean & $\mathrm{N}$ & Std. Deviation & Std. Error Mean \\
\hline Pair 1 & $\begin{array}{l}\text { Pretest Kelompok } \\
\text { Eksperimen }\end{array}$ & 11.84 & 32 & .723 & .128 \\
\cline { 2 - 6 } & $\begin{array}{l}\text { Posttest Kelompok } \\
\text { Eksperimen }\end{array}$ & 14.97 & 32 & .822 & .145 \\
\hline Pair 2 & \begin{tabular}{lllll} 
Pretest Kelompok Kontrol \\
\cline { 2 - 6 }
\end{tabular} & 11.97 & 30 & .809 & .148 \\
\hline
\end{tabular}




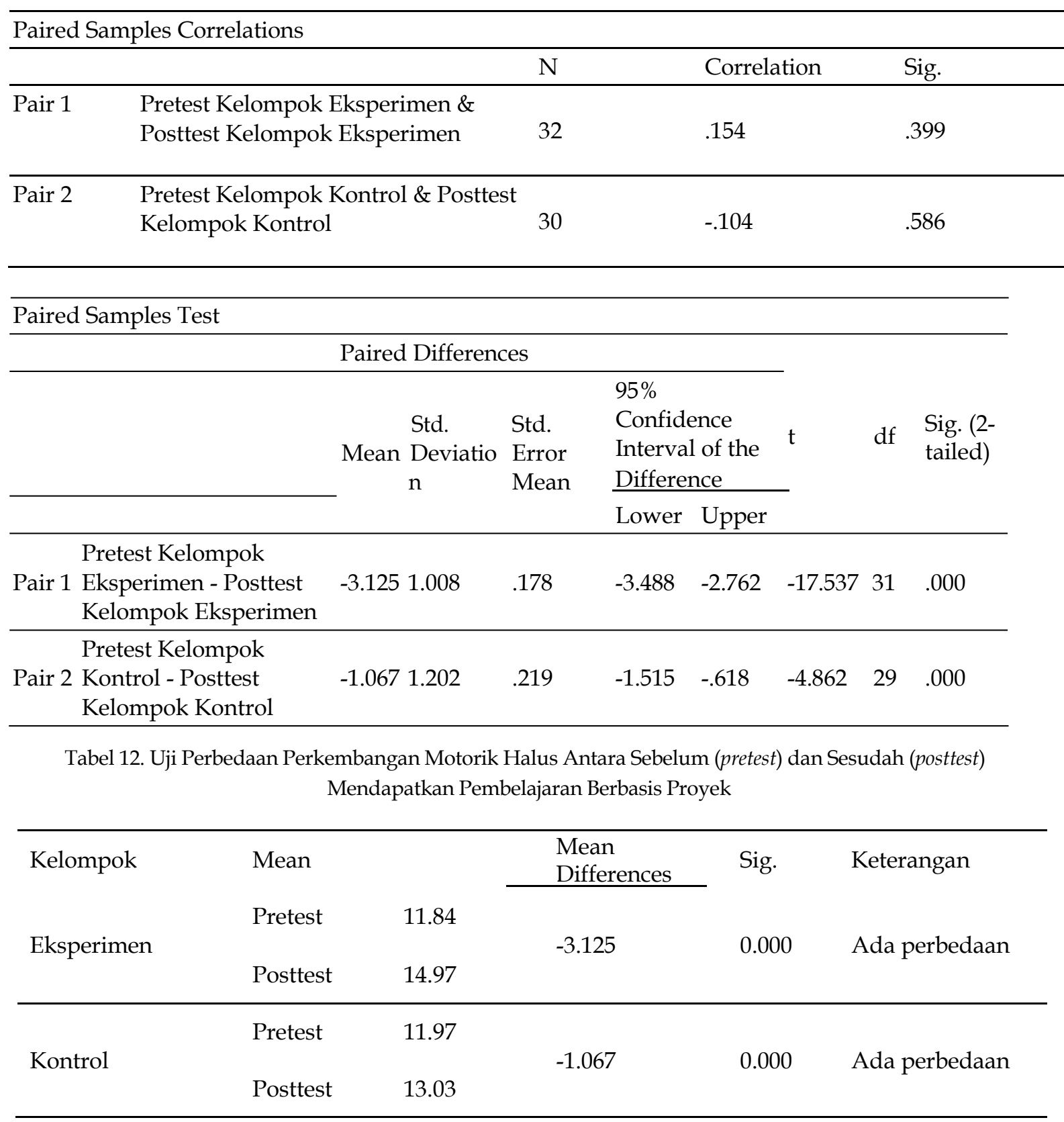

Berdasarkan hasil pada uji beda dengan Paired t test, maka didapatkan nilai Sig. Sebesar 0.000 yang berarti nilai hitung lebih kecil dari 0.05, maka Ho ditolak dan $\mathrm{H}_{\mathrm{a}}$ diterima yang berarti ada perbedaan perkembangan motorik halus antara sebelum (pretest) dan sesudah (posttest) mendapatkan Pembelajaran Berbasis Proyek pada kelompok eksperimen dan kelompok kontrol.

Jika dilihat dari nilai rata-rata, perkembangan motorik halus sesudah diberi Pembelajaran Berbasis Proyek lebih besar daripada perkembangan motorik halus sebelum diberi Pembelajaran Berbasis Proyek yaitu 14.97>11.84 pada kelompok eksperimen dan 13.03>11.97 pada kelompok kontrol. Hal ini berarti Pembelajaran Berbasis Proyek yang diberikan pada siswa RA Kecamatan Plemahan Kabupaten 
Kediri lebih efektif daripada pembelajaran seperti biasanya (menggunakan media gambar dan penjelasan secara verbal).

\subsubsection{Pengaruh Pembelajaran Berbasis Proyek terhadap Perkembangan Sosial Emosional}

Hasil penelitian memperlihatkan adanya perbedaan perkembangan sosial emosional antara sebelum (pretest) dan sesudah (posttest) mendapatkan Pembelajaran Berbasis Proyek pada kelompok eksperimen. Jadi dapat dikatakan terdapat pengaruh yang signifikan pada pembelajaran dengan menggunakan Pembelajaran Berbasis Proyek terhadap perkembangan sosial emosional anak. Hasil penelitian ini juga selaras dengan temuan Kusadi ${ }^{17}$ yang menyatakan bahwa Pembelajaran Berbasis Proyek dapat meningkatkan keterampilan sosial dan kreativitas pada siswa tingkat menengah, dan pada tunagrahita sebagaimana temuan Fadila ${ }^{18}$. Demikian halnya dengan pada anak usia 4-5 tahun, metode ini juga bekerja secara efektif.

Berdasarkan tabel 4.10 hasil uji beda dengan Paired $t$ test, didapatkan nilai Sig. Sebesar 0.000 yang mana nilai ini lebih kecil dari 0.05 , maka tolak $\mathrm{H}_{\mathrm{a}}$ dan terima $\mathrm{H}_{0}$ yang berarti ada perbedaan perkembangan sosial emosional antara sebelum (pretest) dan sesudah (posttest) mendapatkan Pembelajaran Berbasis Proyek. Dilihat dari nilai rata-rata, perkembangan sosial emosional sesudah diberikan Pembelajaran Berbasis Proyek lebih besar daripada perkembangan sosial emosional sebelum diberi Pembelajaran Berbasis Proyek yaitu 26.03>20.44 pada kelompok eksperimen. Hal ini diketahui jika terdapat pengaruh perlakuan (treatment) Pembelajaran Berbasis Proyek terhadap perubahan yang terjadi antara sebelum dan sesudah treatment dengan nilai negatif. Hal ini berarti treatment Pembelajaran Berbasis Proyek memiliki pengaruh negatif terhadap perubahan skor pretest (skor pretest lebih rendah jika dibandingkan dengan skor posttest) maka hal tersebut dapat dimaknai treatment Pembelajaran Berbasis Proyek yang diberikan efektif dalam meningkatkan skor posttest.

Hal tersebut memperkuat temuan temuan penelitian sebelumnya sebagaimana temua Fadila ${ }^{19}$, Kusadi ${ }^{20}$, Yulianti ${ }^{21}$, dan juga Anisa Yunita Sari ${ }^{22}$ bahwa kelompok dapat mencapai kesuksesan sosial emosional dengan permainan Pembelajaran Berbasis Proyek. Dengan permainan ini, anak berhasil dalam komunikasi interpersonal. Masing-masing anak akan berkomunikasi untuk bekerjasama mencari

17 Kusadi, Sriartha, and Kertih, “Model Pembelajaran Project Based Learning Terhadap Keterampilan Sosial Dan Berpikir Kreatif."

18 Sefni, "EFEKTIFITAS METODE PROYEK PADA PEMBELAJARAN KETERAMPILAN BAGI ANAK TUNAGRAHITA SEDANG KELAS X SMALB DI YPAC SUMBAR (Quasi Eskperimen)."

19 Sefni.

${ }^{20}$ Kusadi, Sriartha, and Kertih, “Model Pembelajaran Project Based Learning Terhadap Keterampilan Sosial Dan Berpikir Kreatif."

21 Yulianti, Hartono, and Santoso, “DESAIN PEMBELAJARAN BERBASIS PROYEK PADA MATERI PENYAJIAN DATA DI KELAS IX ."

22 Sari, “IMPLEMENTASI PEMBELAJARAN PROJECT BASED LEARNING UNTUK ANAK USIA DINI.” 
tahu apa yang diperlukan untuk mempertahankan telur di atas nampan. Melalui permainan ini pula, anak akan belajar memahami bahwa kesuksesan itu tidak bisa dicapai oleh seorang diri melainkan butuh bantuan dan kerjasama orang lain.

Temuan ini sekali lagi membuktikan kebenaran teori Catron dan Allen ${ }^{23}$ bahwa bermain merupakan sarana yang penting dalam pengembangan kemampuan dalam melakukan sosialisasi dan mampu memperluas rasa peduli terhadap yang lain serta dapat mengurangi sifat egosentrisme. Dengan bermain maka dapat menumbuhkan dan meningkatkan rasa sosialisasi yang terjadi pada anak.

Berdasarkan beberapa uraian di atas dapat dipaparkan bahwa Pembelajaran Berbasis Proyek dalam perkembangan sosial emosional dapat meningkatkan pembelajaran anak di dalam kelas.

\subsubsection{Pengaruh Pembelajaran Berbasis Proyek terhadap Perkembangan Motorik Halus}

Pada hasil penelitian, menunjukkan bahwa ada perbedaan dalam perkembangan motorik halus antara sebelum (pretest) dan sesudah (posttest) mendapatkan Pembelajaran Berbasis Proyek pada kelompok eksperimen. Dengan kata lain, terdapat pengaruh yang signifikan antara metode pembelajaran perkembangan motorik anak dengan menggunakan proyek. Hal ini mendukung pendapat Fadila ${ }^{24}$, Kusadi ${ }^{25}$, Yulianti ${ }^{26}$, Anisa Yunita Sari ${ }^{27}$, dan Bambang ${ }^{28}$ bahwa melalui Pembelajaran Berbasis Proyek, siswa dapat meningkatkan kemampuan motorik dengan cara belajar menyangga nampan dan mengendalikan telur agar tetap berputar di atas nampan selama durasi yang ditentukan.

Berdasarkan hasil uji beda dengan Paired $t$ test, didapatkan nilai Sig. Sebesar 0.000 yang nilainya lebih kecil daripada 0.05 , maka tolak $\mathrm{H}_{\mathrm{a}}$ dan terima $\mathrm{H}_{0}$ yang berarti ada perbedaan perkembangan motorik halus antara sebelum (pretest) dan sesudah (posttest) mendapatkan Pembelajaran Berbasis Proyek pada kelompok eksperimen.

Dilihat dari nilai rata-ratanya, perkembangan motorik halus sesudah diberi Pembelajaran Berbasis Proyek lebih besar daripada perkembangan sebelum diberikan

${ }^{23}$ Carol Elaine. Catron and Jan. Allen, Early Childhood Curriculum: A Creative Play Model (Upper Saddle River, N.J.: Pearson/Merrill Prentice Hall, 2008).

${ }^{24}$ Sefni, "EFEKTIFITAS METODE PROYEK PADA PEMBELAJARAN KETERAMPILAN BAGI ANAK TUNAGRAHITA SEDANG KELAS X SMALB DI YPAC SUMBAR (Quasi Eskperimen)."

${ }^{25}$ Kusadi, Sriartha, and Kertih, "Model Pembelajaran Project Based Learning Terhadap Keterampilan Sosial Dan Berpikir Kreatif."

26 Yulianti, Hartono, and Santoso, "DESAIN PEMBELAJARAN BERBASIS PROYEK PADA MATERI PENYAJIAN DATA DI KELAS IX."

27 Sari, "IMPLEMENTASI PEMBELAJARAN PROJECT BASED LEARNING UNTUK ANAK USIA DINI."

28 Waluyo, "UPAYA MENINGKATKAN PRESTASI BELAJAR, KEMAMPUAN PRESENTASI DAN DISKUSI MATERI KEUNGGULAN LOKASI INDONESIA PELAJARAN IPS, DAN SIKAP SISWA KELAS VIII.B UPTD SMPN 4 METRO MELALUI PEMBELAJARAN BERBASIS PROYEK DENGAN PENGUATAN DISKUSI TA 2019/2020." 
Pembelajaran Berbasis Proyek yaitu 14.97 $>11.84$. Hal ini berarti sesudah diberi Pembelajaran Berbasis Proyek pada siswa RA kecamatan Plemahan kabupaten Kediri terjadi peningkatan perkembangan motorik halus, dimana peningkatan tersebut cukup besar, sehingga secara uji statistik menunjukkan adanya perbedaan yang signifikan. Hal ini diketahui ada pengaruh yang terjadi antara perlakuan (treatment) Pembelajaran Berbasis Proyek sebelum dan sesudah treatment, namun jika didasarkan pada nilai perbedaan skor hasil pengukuran pre dan posttest (mean differences) menunjukkan nilai negatif. Ini berarti, Treatment Pembelajaran Berbasis Proyek yang diberikan cukup efektif dalam meningkatkan skor posttest. Hal tersebut membuktikan kebenaran temuan Jonas (2006) yang menjelaskan bahwa Pembelajaran Berbasis Proyek mengembangkan komunikasi dan kerjasama di bidang pendidikan yang luas.

Dari penjabaran di atas dapat diperoleh analisis bahwa Pembelajaran Berbasis Proyek dapat meningkatkan perkembangan motorik halus anak di kelas. Selain itu, Pembelajaran Berbasis Proyek juga sesuai diberikan pada anak usia 4-5 tahun seperti pendapat Sumantri ${ }^{29}$ melatih adanya kemampuan untuk melakukan koordinasi antara mata dengan tangan dan kemampuan daya lihat pada anak merupakan tujuan dari aktivitas kemampuan motoric halus anak usia Taman Kanak-kanak. Usaha mempertahankan telur di atas nampan akan melatih kemampuan anak melihat ke kiri, ke kanan, ke atas dan ke bawah sehingga akan membantu persiapan membaca awal anak.

\section{KESIMPULAN}

Berdasarkan hasil paparan di atas, maka dapat ditarik kesimpulan tentang pengaruh perkembangan sosial emosional dan motorik halus pada anak usia 4-5 tahun di RA Kecamatan Plemahan Kabupaten Kediri, adalah sebagai berikut: Pertama, Terdapat pengaruh Pembelajaran Berbasis Proyek terhadap perkembangan sosial emosional pada anak usia 4-5 tahun RA Kecamatan Plemahan Kabupaten Kediri. Hal ini diketahui dari adanya perbedaan perkembangan sosial emosional antara sebelum (pretest) dan sesudah (posttest) mendapatkan pembelajaran Metode Proyek. Perkembangan sosial emosional sesudah diberikan pembelajaran Metode Proyek lebih tinggi daripada perkembangan sosial emosional sebelum diberi pembelajaran Metode Proyek.

Kedua, terdapat pengaruh Pembelajaran Berbasis Proyek terhadap perkembangan motorik halus pada anak usia 4-5 tahun RA Kecamatan Plemahan Kabupaten Kediri. Hal ini diketahui dari adanya perbedaan perkembangan motorik halus antara sebelum (pretest) dan sesudah (posttest) mendapatkan treatment. Perkembangan motorik halus sesudah diberikan Pembelajaran Berbasis Proyek lebih

${ }^{29}$ Sumantri, Model Pengembangan Keterampilan Motorik Anak Usia Din. 
tinggi daripada perkembangan motorik halus sebelum diberi pembelajaran Metode Proyek.

\section{REFERENSI}

Anita, Yus. Penilaian Perkembangan Belajar Taman Kanak-Kanak. Jakarta: Kencana, 2012. Baron, Robert A, and Gideon D Markman. "Beyond Social Capital: The Role of Entrepreneurs' Social Competence in Their Financial Success." Journal of Business Venturing 18, no. 1 (January 2003): 41-60. https:// doi.org/10.1016/S0883-9026(00)00069-0.

Catron, Carol Elaine., and Jan. Allen. Early Childhood Curriculum: A Creative Play Model. Upper Saddle River, N.J.: Pearson/Merrill Prentice Hall, 2008.

Cooper, Janice L., Rachel Masi, and Jessica Vick. "Social-Emotional Development in Early Childhood: What Every Policymaker Should Know." Young Children, 2009. https:/ / doi.org/https:/ / doi.org/10.7916/D83B67VS.

Fadillah. Implementasi Kurikulum 2013 Dalam Pembelajaran SD/MI, SMP/MTs, Dan SMA/MAN. Yogyakarta: Ar-Ruzz 2014. https:// onesearch.id/Record/IOS3605.INLIS000000000012011.

İman, Esra, Şahin Danişman, Zeynep Demircan, and Dilara Yaya. “The Effect of the Montessori Education Method on Pre-School Children's Social Competence Behaviour and Emotion Regulation Skills." Early Child Development and Care 189 (October 26, 2017): 1-15. https:/ / doi.org/10.1080/03004430.2017.1392943.

Kusadi, Ni Made Risa, I Putu Sriartha, and I Wayan Kertih. "Model Pembelajaran Project Based Learning Terhadap Keterampilan Sosial Dan Berpikir Kreatif." Thinking Skills and Creativity Journal 3, no. 1 (2020): 18-27. https://doi.org/http://dx.doi.org/10.23887/tscj.v3i1.24661.

Made, Wena. Strategi Pembelajaran Inovatif Kontemporer: Suatu Tinjauan, Konseptual Operasional. Jakarta: PT Bumi Aksara, 2011.

Mansur, Ahmad. Metode Penelitian Dan Teknik Penulisan Laporan Karya Ilmiah. Bandung: PAAP FEB-UNPAD, 2011.

Nugraha, Ali. Pengembangan Pembelajaran Sains Pada Anak Usia Dini. Jakarta: Depdiknas (Dit.PPTK \& KPT), 2005.

Piek, Jan P., Grant B. Baynam, and Nicholas C. Barrett. “The Relationship between Fine and Gross Motor Ability, Self-Perceptions and Self-Worth in Children and Adolescents." Human Movement Science 25, no. 1 (February 2006): 65-75. https://doi.org/10.1016/j.humov.2005.10.011.

Prayuanti, Endah. "Peningkatan Kemampuan Bekerjasama Melalui Metode Bermain Pada Kelompok B Di TK PKK 54 Pucung Pendowoharjo Sewon Bantul." FIP UNY, 2014.

Sari, Anisa Yunita. "IMPLEMENTASI PEMBELAJARAN PROJECT BASED LEARNING UNTUK ANAK USIA DINI." MOTORIC 1, no. 1 (April 28, 2018): 10.https://doi.org/10.31090/paudmotoric.v1i1.547.

Sefni, Fadila. "EFEKTIFITAS METODE PROYEK PADA PEMBELAJARAN KETERAMPILAN BAGI ANAK TUNAGRAHITA SEDANG KELAS X SMALB 
DI YPAC SUMBAR (Quasi Eskperimen)." Jurnal Penelitian Pendidikan Khusus 3, no. 3 (2014). https:/ / doi.org/https://doi.org/10.24036/jupe38440.64.

Sumantri, M.S. Model Pengembangan Keterampilan Motorik Anak Usia Din. Jakarta: Dinas Pendidikan, 2005.

Waluyo, Bambang. "UPAYA MENINGKATKAN PRESTASI BELAJAR, KEMAMPUAN PRESENTASI DAN DISKUSI MATERI KEUNGGULAN LOKASI INDONESIA PELAJARAN IPS, DAN SIKAP SISWA KELAS VIII.B UPTD SMPN 4 METRO MELALUI PEMBELAJARAN BERBASIS PROYEK DENGAN PENGUATAN DISKUSI TA 2019/2020." Jurnal Guru Indonesia 1, no. 4 (July 12, 2021). https:/ / doi.org/10.24127/jgi.v1i4.1142.

Winarno, Jacinta. "Emotional Intelegence Sebagai Salah Satu Faktor Penunjang Prestasi Kerja." Jurnal Manajemen Maranatha 8, no. 1 (2008).

Yulianti, Yusuf Hartono, and Budi Santoso. "DESAIN PEMBELAJARAN BERBASIS PROYEK PADA MATERI PENYAJIAN DATA DI KELAS IX ." Numeracy 2, no. 2 SE-Articles (October 31, 2015): 1-12. https://doi.org/10.46244/numeracy.v2i2.163.

Yusuf, Syamsu. Psikologi Perkembangan Anak Dan Remaja. Bandung: PT Remaja Rosdakarya, 2007.

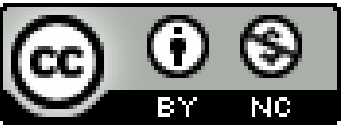

(C) 2021 by the authors. Submitted for possible open access publication under the terms and conditions of the Creative Commons Attribution-NonCommercial 4.0 International License (CC BY NC) license (https://creativecommons.org/licenses/by-nc/4.0/). 